\title{
Two discourses: Researchers and policy-making in higher education
}

\author{
JUSSI VÄLIMAA ${ }^{1} \&$ DON F. WESTERHEIJDEN ${ }^{2}$ \\ 'University of Jyväskylä, Institute for Educational Research, Jyväskylä, Finland; \\ ${ }^{2}$ University of Twente, Center for Higher Education Policy Studies, Enschede, The Netherlands
}

\begin{abstract}
The theme of this article focuses on how policy discourse and research discourse meet in contract research in higher education. The interplay of these discourses has consequences for researchers who have to balance conflicting demands, which we view as links between research and policy cycles. Two evaluation studies on the introduction and effects of new policy instruments are discussed, focusing on the interaction between policy needs, and research design. The examples are taken from policies in the development towards increasing self-regulation in higher education, of which Finland and the Netherlands are interesting examples in the European context.
\end{abstract}

\section{Introduction: Two discourses and two cases}

The relationship between policy makers and contract researchers belongs to the 'hidden' issues in social sciences. Sometimes it surfaces, but the authors feel that this issue too often does not come up in discussion, although contract research, and especially government-funded contract research takes place even more often in the field of higher education than is usual in other fields of social sciences. The issue at hand is whether or not researchers can carry out independent scholarly research and retain all the integrity that follows, and simultaneously meet the needs of the principals. Following from their different positions and interests, policy makers and researchers have different ideas about what a research project can or should do. At a conceptual level these differences in expectations and attitudes can be interpreted as different discourses with various or even conflicting views on the purposes of research and on the use of its results. In this paper we wish to characterize the two discourses in the European context, to probe into their interconnectedness, illustrated by our experiences in two recently completed contract research projects.

'Discourse' has many overlapping and even conflicting definitions formulated from various theoretical perspectives (cf. Macdonell 1986). Introduced mainly by Foucault (1972) to social sciences it has been used in a variety of ways in different disciplines (cf. Van Dijk 1985). Following a more linguistic approach, discourse can be used as an analytical method in the interpretation of texts to reveal the motives and purposes of a writer or a speaker (cf. Van Dijk 1985). This may be called textually-oriented discourse analysis (Fairclough 1992, 37). The other main stream of applying 'discourse', which will be followed here, defines the term as a frame of reference, or a cognitive structure (Wagner and Wittrock 1990, 333), pointing to the discursive construction of social subjects and knowledge. This use of the concept emphasizes the interactive nature of creating and understanding a 
reality (Fairclough 1992, 3). In this approach the discursive creation of reality is inseparable from the ways of understanding reality.

By research discourse we mean the intellectual activities and debates based on empirical or theoretical approaches to higher education as a phenomenon. Participants in this discourse are not necessarily only researchers, because discourse is not defined by enumerating the actors, but by characterizing the elements that form the intellectual binding force. The research discourse, then, is characterized by its analytical and theoretical approach to higher education guided by scholarly motives and willingness to draw conclusions based on data. In the policy discourse the expectations of the participants (as a rule: decision-makers) are inspired by the instrumental value of knowledge produced by research. The policy discourse is thus focused on using, among other available sources of information, the outcomes of research in making decisions concerning higher education.

A contract explicates a relationship of mutual dependency. From the viewpoint of the principals, a contract means that policy makers are dependent on researchers because they do not have the necessary expertise at their disposal. From the researchers' viewpoint, however, contract research implies a dependency relation of the researchers that may have direct effects on the research methods and outcomes. But even if the principals behave ethically and give the researchers all the freedom they can be given in contract research, two effects still remain that must be taken into account. First, if it is not a 'one shot' relationship and the researchers are for a significant part of their budget dependent on contract research, they have to consider their reputation in the policy discourse, because it influences their chances of obtaining further contracts from this principal (or another) in the future. Reporting favourable outcomes from the point of view of the principal, and choosing appropriate theories and methods to help 'massage' reality into a favourable mould, may prove a dangerous lure in this situation. Second, even if researchers remain well-entrenched within the research discourse and choose theories and methods solely for their appropriateness for the object of research, they still cannot choose the object of research freely. Thus, scientific relevance, i.e. the question whether research on a certain topic will advance the state of knowledge in the field, is superseded in contract research by the (policy) needs of the principal. Societal relevance, or relevance for (governmental) policy is then the usual argument. Behind these arguments, the relevance of research results in intragovernmental or organizational politics plays a significant role as well (cf. Pfeffer 1981; Lieshout and De Vree 1985).

The position of researchers in contract research at a relevant level may be articulated on three levels: the local level, the national policy level and the scientific community level. All these levels, in turn, can frame the research and set expectations for the results achieved during the research.

If researchers carry out a research project on their own institution, the local level is relevant. At the local level the tensions are defined by two factors. On the one hand, if researchers study their own higher education institution, they may be involved in the local situation. Does this hinder their functioning as researchers? On the other hand, having inside knowledge about the processes going on in the 
institution provides the advantage of getting 'local knowledge' of the meanings given to facts in the local context (Geertz 1983).

At the national policy level the researcher's position is affected by the political nature of the issue studied. The possibly contested nature of the issue (as seen from the policy discourse) may influence the practical research issues taken into account. Is this a real threat to research? There may also be positive aspects to having to interact with actors in a different discourse: at which stages of the research project is the interconnection of the two discourses most fruitful for each party? We might suggest, for instance, that exchanging concepts and ideas may be more important in this respect than the actual research results. But the question for the researcher remains: how to maintain a balance between relevance in policy discourse and in research discourse?

The third level, i.e. that of the national and international (disciplinary) scientific community, is party to the tensions mentioned in the previous paragraph, because of the social demands the scientific communities make on the researcher. Since the social organization of scientific communities is not our main topic, we merely refer to the literature, e.g. Kuhn (1962 [1970]), Whitley (1984) and Becher (1989).

The local, policy and scientific community tensions may play a role in all stages of the research process: formulation of the research problem (policy relevance versus research relevance), choice of methods (convincing external audiences versus methodology) and consequently the types of conclusions that can be drawn, ways of reporting ('ghost-writing' a policy paper, convincing policy makers, or stating 'plain facts'), and the uses made of the report (by policy makers and by researchers).

Based on the previous discussion we can formulate the main problem in this paper. First, do the two discourses meet? Second, if, as we suppose, the discourses meet, how do they interact with each other? We shall try to answer these questions by looking at two cases. The cases chosen, from Finland and from the Netherlands, are interesting examples of the emerging strategy of self-regulation (Van Vught 1989). Self-regulation is a trend in many continental European higher education systems traditionally characterized by strong and detailed governmental steering (Clark 1983). An important role as initiator of changes can be expected from governments in the continental model, and indeed, despite the emergence of selfregulation, the two instances we shall elucidate, were initiated by national governments. After a brief description of the cases, we shall return to the general questions presented in the introduction, in the comparison of the cases and in the conclusions.

\section{Free allocation of teaching resources in the Finnish context}

Experiments on the free allocation of teaching resources were initiated at the Helsinki School of Economics in 1988 and at the University of Jyväskylä in 1989. Following the idea of increasing the autonomy of universities, these reforms have aimed at increasing flexibility on individual, basic unit and institutional levels (cf. 
Becher and Kogan 1992) to allocate teachers' time better between academic tasks by abolishing statutes that regulated the teaching load in a very detailed manner. Before the experiments it was stated that professors must give four lectures per week, the teaching load of associate professor was six lectures per week, etc. (Välimaa 1992). It is important to note that the agreement to initiate the experiments was made between the central authorities (Ministry of Education) and the academic labour unions, and not between the Ministry and the higher education institutions (cf. Välimaa 1992).

On the national level, the free allocation of teaching resources experiment has been a politically hot issue during the last six years. In line with the Finnish reform strategy 'learning by experimenting' (described later) the experiment was intended to develop into a system-wide practice within a couple of years. The labour unions have, however, resisted this mainly because of the fear of loosing their national power, in case the right to negotiate would be transferred to the local level. The higher education institutions have, in turn, been willing to initiate the experiment because it would increase the flexibility inside the institutions. Together with a more flexible budgeting system the experiment provides effective managerial tools also to the university management. Finally, during the last year of the experiment (in 1994) the higher education institutions were authorized by the Ministry of Finances to negotiate on academic working conditions at the local level. Labour organizations have, however, resisted this authorization.

\section{The Finnish 'learning by experimenting' reform strategy}

Experimenting is the usual way to initiate reforms in Finnish higher education. Normally a reform is initiated as a pilot experiment at an institution (or a few institutions) with the purpose of expanding it within a few years into a system-wide practice (more on this, Välimaa 1994b).

The Finnish reform strategy results mainly from the balance of power among the many actors in the field of higher education policy. On the one hand, all actors can agree on an experiment, because it is meant to be only an 'experiment'. On the other hand, starting an experiment gives time to different actors to accumulate information and form opinions on the issue. An experiment is also good 'advertisement' for both the supporting and the resisting actors, because they can all say they take the need of the reform very seriously.

The governmental bodies (Ministry of Education, Ministry of Finance) are normally in favour of the reform and, consequently, the labour unions or higher education institutions resist the reform. The critical moments in this Finnish strategy of 'learning by experimenting' come up when the supporters of the reform would like to expand the experiment into system-wide practice. This is the moment when the other actors have to formulate their opinions.

As to free allocation of teaching resources, the first critical phase was reached after two years of experimentation in 1991, when the Ministry of Education wanted to expand the flexible model to all Finnish universities. Ten out of twenty 
institutions would have liked to join the experiment. The labour unions, however, resisted the expansion stating that they wanted to have more information on the reform. And that was when both sides started to formulate expectations on the follow-up research.

\section{The follow-up study of the experiment}

The follow-up study was initiated in 1988 at the University of Jyväskylä simultaneously with the planning of the coming reform. At the beginning of the follow-up study the main emphasis was at the local level. On the one hand, information was gathered for the needs of the steering committee of the experiment to support their decision-making. On the other hand, the aim of the research was to reveal and to conceptualize what is taking place at the university. Actually, both aims required the analysis of processes of change taking place at the University of Jyväskylä. This interpretation of the tasks of the researchers has, in turn, directed the follow-up research towards a comprehensive approach to understand and explain the changes. On the basis of the local data it began to look as if the academic communities (departments and even faculties) could be seen as cultural entities with shared values and norms in understanding the nature of the innovation (cf. Välimaa 1991). The interest in academic and disciplinary cultures connected the experiment with the international discussion on academic cultures (cf. Välimaa 1992).

Simultaneously with this local role, the research team attempted to provide information for all actors in the national higher education system. At the national level the team has recognized the labour unions, the Ministry of Education (and also the Ministry of Finance), higher education institutions and academic communities as actors interested in the outcome of the experiment. This recognition of different actors has influenced the data gathering during the follow-up study.

The follow-up was executed at the Institute for Educational Research (IER) mainly for two reasons. First, IER is the national centre of educational studies in Finland. For this historical reason the institute has also been responsible for followup studies on Finnish higher education reforms since the '70s. It is assumed that IER is experienced in doing follow-up studies on higher education. Second, more practically, IER is situated at the University of Jyväskylä, one of the institutions involved in the experiment.

\section{Position of the researcher}

At the local level the tensions are defined by two facts. On the one hand, being members of the community the research team is researching, we may be too involved in the goals and aims of the reform or those of the university to remain independent. On the other hand, we have inside knowledge about the processes going on at the university. In this sense the team has 'local knowledge' of the meanings given to the facts in the local context as opposed to 'universal knowledge' 
(cf. Geertz 1983). This local knowledge, in turn, acts as an interpretative framework when the processes in the academic communities are analyzed.

At the national level our researchers' position has been affected by the fact that the innovation examined has been and is a controversial political issue in the higher education field. This fact has influenced the practical research issues considered. To serve the labour union interests, the team has analyzed changes in teachers' work load and in the structure of their tasks. To serve the national academic audiences we have polled the opinions of the academic teachers at Jyväskylä University on the experiment by way of a questionnaire. In other words, the political interests have led the follow-up research towards practical matters, putting aside the more theoretical issues.

The issue that seems to worry most the Finnish community of social scientists focuses on suspicions on the relationship between the researchers and the funding body. Namely, how much does the interest of the funding body influence the researcher? These concerns, in turn, have led social scientists connected with the project to a critical attitude about the outcome of the follow-up study because it is 'only contract research'. Inside the follow-up project group these suspicions have sparked off many theoretical discussions, resulting e.g. in articles like this one.

In principle, the Ministry of Education controls the research process very accurately, because we have to apply for funding of the follow-up once a year. In practice, however, we have had free hands in focusing the research on theoretically interesting dimensions of the change processes taking place at Jyväskylä University. On the one hand, the research team has experienced the attitude of the Ministry of Education very supportive, because they have not interfered with our theoretical or practical issues. On the other hand, we can never be absolutely certain about its decision to fund follow-up research. In this sense, the follow-up study is based on continuous uncertainty.

\section{On the methods and results of the follow-up study}

The ways of gathering data during the follow-up study are mainly qualitative methods (interviews and interpretation of written sources), supported by quantitative data. The quantitative data are mainly used as descriptive information, whereas the qualitative data are used in the search for meanings, to analyze the questions raised by the quantitative data.

According to the follow-up study, at Jyväskylä University the results of the flexible allocation of teaching resources are multiple and varied. The experiment has increased innovations in teaching (reported in Välimaa and Vuorinen 1991 and in Välimaa 1994a), it has promoted cooperation between departments and between individuals. Furthermore, during the experiment the teaching load of the teachers has not decreased remarkably, but the profiles of the work loads have become more flexible within different teacher groups. Even though outcomes are only positive at the local level, labour union activists have interpreted the same outcomes as a possible threat to academic freedom in order to prevent the implementation of the 
experiment to other universities (Välimaa 1992 and 1993). In the analysis of the various processes of change and in debates on the experiment we have explained the variation of opinions through three different discourses pointing to the variety of possible ways in understanding the 'true nature' of this kind of loose reform (cf. Välimaa 1993).

At a conceptual level the follow-up study has created a concept describing the nature of academic communities. By introducing the new concept 'academic working culture' (toimintakulttuuri) we were able to analyze the functioning of the University by explaining the differences both in actions and in attitudes to experimentation with the help of academic cultures (cf. Konttinen and Välimaa 1990). The term was rapidly utilized in various societal discourses.

At the national level the major result of the experiment is the right for each university, granted in 1994, to negotiate flexible work loads at the institutional level. In Finland, this is a remarkable reform, and it may increase significantly the autonomy of higher education institutions. Although the decision was made in a political process, it is probable that the follow-up research has contributed to this solution. It is, however, difficult to verify a causal relationship between the policymaking and the research project.

At the local level it seems that because of the experiment the departments and individual teachers have become more conscious of the quality of teaching and research during the experiment (cf. Välimaa 1993). Though this notion is also influenced by many external factors, such as budget cuts and quality assessment processes at institutional and disciplinary levels, the experiment has helped in promoting the creation of a "quality culture' inside Jyväskylä University. An important element in this process is the ownership of the academic basic units in allocating their resources (cf. Sallinen, Konttinen and Panhelainen 1993).

\section{Quality assessment of teaching in the Netherlands}

\section{Quality assessment in Dutch higher education}

Quality assessment has been an issue in Dutch higher education since the 1980s. Quality assessment of education entered the political agenda as part of the new, self-regulation oriented policy of the Dutch government, first stated in the policy paper Higher Education: Autonomy and Quality (Ministry of Education and Science 1985). In exchange for a larger measure of administrative autonomy the universities collectively would maintain and enhance their levels of quality in education and assure that to society (an assessment procedure for research programmes had already been in operation since 1982). Quality assessment of teaching then appeared on a systematic and nationwide scale in 1988, when the Association of Universities in the Netherlands (VSNU) effected this new responsibility. In 1990 a parallel system of quality assessment was introduced by the hbo Council, the VSNU counterpart for the 'polytechnics' or the non-university sector (Hbo Council 1990). The manner of introduction of the VSNU system was 
agreed between the Ministry of Education and Science and the VSNU. It proceeded on a 'learning by doing' basis, which, in itself, was a change of policy following the new 'steering philosophy'. The first round, in 1988, was a pilot project. The VSNU, founded only a few years before, through the quality assessment procedure affirmed its position as a buffer organization of, and for, all universities. For the vsnu, the quality assessment procedure quickly became a very important topic and it now is the single most-important item in its budget (approximately $30 \%$ of the total budget in 1994). This is not to the same extent the case for the hbo Council, which had already established its position as a buffer organization for the hbo institutions.

The VSNU quality assessment system, which did not basically change after the pilot project (VSNU 1988, 1990), consists of an external visiting committee for each discipline or cluster of study programmes, operating nationwide. To prepare for the visiting committee, each study programme is required to write a self-evaluation. When the visiting committee has visited all study programmes in its 'cognate area', it writes a final, public report. In it, the visiting committee addresses the strong and weak points of each study programme and states recommendations, but does not give an explicit comparison or a ranking of the programmes. The visiting committee's judgements and the self-evaluations are intended, in the first place, to maintain and improve the quality of the study programme. Accountability to the government and to society in general is a secondary goal (Vroeijenstijn and Acherman 1990).

\section{The 'effects' research project: Methods}

The primary goal, quality maintenance and enhancement, raises the question to what extent the results of the quality assessments are utilized, in other words: are the intended effects of the existing quality assessment system realized? This was the question the Dutch Ministry of Education and Science was interested in when the system had been operating in the university sector for some three years, in 1991-1992. The Ministry commissioned its Inspectorate of Higher Education to carry out a 'midterm review' to answer this question (Inspectorate of Higher Education 1992), and it commissioned a university-based research center, the Center for Higher Education Policy Studies (CHEPS), to carry out a research project in this vein. The original question of the latter project can be formulated briefly as: What are the effects of the quality assessment system on the quality activities of higher education institutions? However, this project was not intended as an evaluation of the evaluation system in the Netherlands, for that would have meant an intrusion on the task of the Inspectorate. Both to avoid this potential problem, and to make the project scientifically more relevant, the second author's team focused not on the quality assessment system as such, but on the quality activities at the study programme and institutional levels. So the research problem was effectively changed into: Which quality activities regarding their teaching are undertaken by higher education institutions in the Netherlands and how has the introduction of a national system of quality assessment influenced the level and type of these activities? This composite research question implies a research design 
with a descriptive component (which activities?) and an explanatory component (how influenced by the national system?). Therefore, the researchers not only made an inventory of the quality activities, but also attempted to deduce explanatory hypotheses on the utilization of evaluation analyses and results from prima facie relevant theoretical approaches, found in the contingency approach and in political economy (e.g. Child 1984; Lieshout and De Vree, 1985). Independent variables associated with higher utilization were: externality of evaluation, small size of study programme, centralization of decision-making power inside the study programme, availability of data (e.g., on student progress), power of evaluators vis$\grave{a}$-vis decision-makers, and involvement of decision-makers in the self-evaluation. A complicating factor, as was realized when developing the theoretical framework, was that during the years the quality assessment system had been in operation, many other policy and environmental changes had taken place at the higher education institutions: it could not be assumed that the context had remained unchanged. Therefore, it was known that it would not be possible to establish causal relationships beyond doubt. Still, both the scientific and policy discourses demanded an approach that aimed at establishing causal links.

The project consisted of two stages. First, all higher education study programmes in the Netherlands were mailed a questionnaire about the activities they performed regarding quality control and quality enhancement, focusing especially on followup activities after the self-evaluation and the external visitation. For although the research question was altered in the preparatory phase, the focus on the effects of the national system of quality assessment could not be abandoned completely. Moreover, it was known from earlier research (Weusthof 1989) that many of the quality activities had been introduced at the higher education institutions in connection with the various national developments. The quantitative data and their analyses were conceived as the primary data source in the research project, especially to test the hypotheses. The second stage consisted of twelve case studies of study programmes selected on the basis of the questionnaire answers. The case studies comprised qualitative analyses of the self-evaluation and visiting committee reports, and several semi-structured interviews (usually three per case) with quality assessment experts in the study programme, faculty and institutional levels. From the beginning, the case studies were viewed as additional data sources, probing deeper into the decision-making processes associated with the follow-up of recommendations resulting from (or anticipating) the internal and external quality assessment process. Thus the relationship between quantitative and qualitative methods is the same as in the Finnish project (primary, respectively, in-depth analysis), but the balance is different, with the quantitative data being more important in the Dutch case (description plus statistical and explanatory analysis, as against mere description).

\section{Main conclusions of the 'effects' research project}

The results of the study are reported in more detail elsewhere (Frederiks, 
Westerheijden and Weusthof 1994). The first, and main, conclusion is that quality management of teaching is an issue that has obtained much more attention than before in Dutch higher education. In general terms, a 'quality culture' may be taking root in the universities and hbo institutions.

Second, quality is not only on the agenda, but also something is being done about it: measures are taken in connection with the self-evaluations and the visiting committee reports. However, measures are not taken in response to every recommendation, nor are the measures taken drastic. This is not meant as a criticism of the present system of quality assessment: The effects of a 'quality culture' cannot, and should not be expected to be immediate and extensive. Quality of education, however important, is only one of many issues in the institutions for higher education. Also, less far-reaching measures may have powerful effects in future years. On the other hand, taking measures does not necessarily lead to the improvement of education, because the relationship between measures and improvement is obscure.

Third, the level of satisfaction with the implementation of the Dutch quality management system within the institutions is fairly high. This is remarkable considering that higher education organizations are often described as relatively autonomous organizations with little inclination to appreciate outside scrutiny. The details of the quality assessment procedure may have been important in this smooth introduction, notably ownership and coordination by the institutions themselves, and a rather indirect link with (financial) sanctions and rewards (cf. Van Vught and Westerheijden 1993). The level of satisfaction is also remarkable in view of the frequent observations by the respondents on how heavy a burden it is to write a self-evaluation report.

\section{Position of the researchers}

Since in this project all principals represent the national level and the 'own' university is not a special subject of study, the position of researchers in the 'effects' project need not be articulated in relation to the local level. This project is funded by the Ministry of Education and Science, which is not the organization operating the national quality assessment system. In the present policy context, there is no direct link whatsoever between the VSNU quality assessment procedure and higher education policy. This implies that the principal for the research contract does not have a vested interest in this form of quality assessment procedure. Yet, after some years of gaining experience, the Ministry became interested in the question whether the quality assessment procedure had the desired effects, or whether it should change its restrained position into a more active one. In other words, there certainly is a policy question to be answered by, among others, this research project.

The choice for the Inspectorate of Higher Education as an agent performing such an evaluation is obvious: the Inspectorate are the 'eyes and ears' of the Ministry as to the operation of the quality assessment procedure (it writes yearly 'meta- 
evaluation' reports on the visiting committees that have operated during the past academic year). And the Inspectorate, which was bypassed by the VSNU in the operation of the quality assessment system in the first place, was only too happy to extend its activities by interpreting its remit this way. Why CHEPS was chosen to carry out a second research project on practically the same topic, can less easily be argued. Let us simply take it for granted that a more government-independent view on the quality assessment system was valued as well. The relationship between the Ministry of Education and Science and CHEPS is a longstanding one: CHEPS is dependent for a significant part of its budget on contract research, which the Ministry of Education and Science provides the most in the Dutch higher education research 'market'. Seen from the Ministry's side: this research institute is one of the less than a handful in the country that could carry out such projects, implying that there is a situation of mutual, even though unequal, dependence.

The relationship between CHEPS and the Inspectorate is more like a one round game: they do not often meet each other in this way. The coordination required for the parallel projects was extensive, however. First, overlap between the research questions was to be avoided, to create cooperation instead of competition. This was another reason for rethinking the research question. Also, the survey instrument was discussed between the researchers and the Inspectorate, and it was used cooperatively. Furthermore, special care was taken to include in the second stage of the project as few as possible of the locations visited by the Inspectorate to broaden the total information base, and to reduce the burden for the higher education institutions involved.

The relationships between the researchers and the other actors at the national level were less direct. Due to unintentional circumstances, there was no systematic consultation of VSNU or hbo Council in the steering committee for this project. Accordingly, those two organizations, which are interested most directly in the national quality assessment procedures, were only informally consulted on the design of the study.

This institutional arrangement of the project organization resulted in a relatively large amount of freedom for the researchers to frame the project. More attention could be given, in this way, to theory-relevant research, as opposed to searching for instrumental, controllable variables. On the other hand, such freedom implied little certainty about the utilization of the research results, until it became evident that they were favourable for the Ministry - which then referred to the growing of a 'quality culture' in its biennial planning document in 1993 (Ministry of Education and Science 1993, 108). Earlier in 1993, between the times of completion of the Inspectorate evaluation and the 'effects' project, the Ministry of Education and Science and the higher education institutions agreed on a more direct feedback procedure on the follow-up given to the recommendations resulting from the external assessments. Without interfering with the assessment procedure or with its improvement orientation, the Ministry thus reinforced the importance it attached to the further establishment of the 'quality culture'. 


\section{Comparison of the two cases: Researching processes of change}

In both research projects reported about in this paper the topic was: effects of the introduction of a policy instrument. The Finnish situation was such that the evaluation research was simultaneous with the introduction of the instrument; in the Netherlands, research started after the fact. Another factor of importance was that the Finnish experiment took place in one location, while in the Netherlands all higher education institutions in the country (about a hundred institutions, with a total of approximately a thousand study programmes) were involved in the implementation of the new instrument. These conditions resulted in different research designs: the project in Jyväskylä existed from the start of the experiment until the post situation, following closely the whole process, in a case study design emphasizing qualitative methods. The Dutch project consisted only of a crosssectional post factum observation, with stress on quantitative methods (survey, statistical analysis). As evaluation research the Finnish project approaches 'illuminative' research and formative evaluation with development goals included in the project, whereas the Dutch project resembles fairly summative evaluation with researchers as external evaluators (Kogan 1989).

The quantitative emphasis in the latter case partly derived from the large number of units involved, partly from the more summative purpose of the study, but - even though unconsciously at the time - partly also from the expectation that the decision-makers, the principals, would want quantitative data. Concise figures are so much easier to handle, and seem to be so much more 'real' and 'hard' than lengthy case descriptions, that we may venture the general rule that European policy-makers prefer figures, hence quantitative research methods. This also applies to the Finnish case, where, although to a lesser extent, quantitative methods were used to underpin the study. However, quantitative cross-sectional data are too superficial if the intricacies of the processes of decision-making in organizations as complex as higher education institutions are the object of research. For instance, they do not easily tell about the anticipation that took place in the Dutch quality assessment procedure: were organizational and curricular changes introduced in many places before the official quality assessment process started, connected or not connected to this quality assessment process? In semi-structured or open interviews, such information could indeed be gathered.

Also, one of the most important conclusions in both cases, namely that a development towards a 'quality culture' seems to be taking place, is based on qualitative methods (i.e. interviews) more than on quantitative data. In the Dutch case, quantitative data could not indicate more than that many activities were initiated after the quality assessment procedure, but without a clear correlation with the recommendations made during the process. They could not reveal that the recommendations given by the visiting committees were not meticulously followed, but did spark off decision-making processes that resulted in taking some action. Interviews were necessary to make this particular interpretation of the (spurious) non-correlation more than just the researchers' guess. However, without the finding of the non-correlation, the researchers' attention might not have been 
drawn to this aspect as clearly; in that sense, the survey approach certainly proved helpful in drawing this conclusion.

Essentially, in both studies presented here, we have been dealing with problems of change. In the Finnish case, we have analyzed both the attitudes of the faculty members on change and the changes that have taken place during the experiment. It seems that important processes are almost 'invisible' in the sense that the changes in the structure of teachers' work have proceeded gradually, and the changes in departments to implement more collective planning practices have taken place step by step. These processes are more like learning processes in the academic communities than sudden revolutions. Therefore, they cannot be easily described by figures and tables, which, nevertheless, are required by decision-makers. This way, the problems of explaining processes are related to difficulties in communication between the problem-oriented research discourse, where change is an interesting methodological issue, and the policy discourse where change is understood as a practical problem.

Methodologically the problem of change concentrates on the question of how to find a control group (cf. Cook and Campbell 1979). Control groups can be sought in time, in place, or in both. Control in time means that we should have had information on the situation before the experiment was initiated to see what has happened during the experiment. The problem with this alternative is that during the process of reform we no longer have independent variables: comparison becomes impossible because the contexts have changed in time (cf. Yin, 1989). It seems, then, that comparison between two separated units (the unit in the experiment and a non-experimental control unit) is an easier task. The problem here, however, is where to find a comparable unit. In the Finnish case study the problem of a control unit emerged during the research process, as the need to compare the improvements at Jyväskylä University with a 'non-experimental university". But because of the lack of a control unit at the beginning of the experiment, we could make comparisons only with data of a national database. Therefore, at this level we were not able to analyze processes, but only to juxtapose the outcomes of the processes at the institutional level. In the Dutch case, the strategies of controls in time and place were attempted in a more direct way, but again both turned out to function imperfectly. On the one hand, we had data on the situation in the universities before the introduction of the quality assessment system (Weusthof 1989). Yet these could be interpreted only as a partial pre situation measurement, because they did not include the hbo sector of higher education, and, more importantly, because that project proceeded from almost - but not exactly the same research question. On the other hand, the study programmes that were not yet subjected to the assessment procedure might be taken as a control group. However, in the university sector this group was very small, and in the hbo sector, where this group was larger, it appeared that once one study programme in an institution had been assessed, this had a 'contaminating' effect on the other study programmes in the institution (awareness of quality and of external assessment was raised considerably). Accordingly, there were not many 'clean' control cases left. This paragraph goes to show that in contract research the demands of the policy 
discourse (starting too late or with a limited question) may render it difficult for the researchers to follow the methodological rules of the research discourse.

\section{Conclusion: Two discourses, two cycles}

Research in the higher education field may be defined by the dependencies on academic fields, on the funding body and on policy relevance. A peculiarity in higher education study may be that it is a multi-disciplinary field of research: the section on disciplinary perspectives in the Encyclopedia of Higher Education (Clark and Neave (eds.) 1992, section V) contains more than twenty different disciplines and fields. This implies that the concept of 'peers' is somewhat ambiguous in higher education research, because there is not a single scientific community in which the researcher is embedded. This, in turn, means that in connections with policy-makers a higher education researcher lacks a solid disciplinary power base, which ' . . has left the area more vulnerable to the vagaries of funders' priorities' as Fulton puts it $(1992,1814-1815)$ than most other fields of social science. The funding bodies, whether they are private or public, are mostly interested in research of politically relevant issues, both if they fund contract research and if it is basic research. As Fulton (1992, 1813-1814) noted: 'It would be an overstatement to suggest that the prosperity and the direction of higher education research are at the mercy of its funders [...] however, a great deal of higher education research has been promoted by external agencies in pursuit of issues of policy concern, and the potential relationship cannot be ignored.' This notion has not, however, led him to reflect on how this situation affects research processes and outcomes.

Traditionally it is argued that methods and results in research processes are in a causal relationship with each other: the questions asked will show the direction of answers received (cf. Bernstein 1988, Popper 1959 [1980]). Without underestimating this argumentation we should like to draw attention to the fact that the position of the researcher may also influence the methodologies chosen and results achieved. Although researchers are never absolutely free to choose their research subjects because of the demands of the scientific community, as among others Kuhn (1962 [1970]) has shown, contract researchers especially (though not only they, as Knorr-Cetina (1981, 81-91) stresses) are funded to investigate politically relevant topics, as in the studies presented above. It is noteworthy that our research processes, methods and even some outcomes resembled each other, although we started from different theoretical and methodological viewpoints. To our minds this convergence is caused by the demands of the policy discourse. Furthermore, the important issue in contract research seems not to be the methodological purity of research, but the combination of different methodologies which enables us to describe the phenomena that are important for the funding body and for the audiences of the research outcomes. In such applied research, the policy discourse dominates the research discourse.

How then, can we describe the differences between the policy discourse and the 
research discourse? The policy discourse is directed by an instrumental interest in knowledge, whereas the research discourse is based on theoretical interest in knowledge. Instrumentalism can be described as the doctrine where in the end empirical theories are nothing but instruments that enable us to act successfully (cf. Popper 1959 [1980], 59). We feel that this characterizes the 'ideal-typical' policy discourse approach to research: how does research help decision-makers to act successfully, i.e. to solve their problems, or to give the relevant audiences the impression their problems have been solved? In policy discourse, it is the tail of political problems that wags the dog of research. This instrumental approach may not be exhibited by all decision-makers all the time, but should be considered as an ideal type characterization in Weber's sense of the word. Equally ideal-typical, and even normative, is the following characterization of the research discourse: " . . the theorist is interested in explanation as such, that is to say, in testable explanatory theories: applications and predictions interest him only for theoretical reasons because they may be used as tests for theories' (Popper 1980 [1959], 59). In more hermeneutical language, the research discourse - based on theoretical selfunderstanding - acts in discursive dialogue with reality to conceptualize 'reality' (Heiskala, 1990, 19-27). Not surprisingly, the different positions of decisionmakers and researchers concerning research in higher education lead to significantly different expectations about the outcomes of research projects. Policymakers are more interested in concrete data, like figures and tables, whereas researchers are more interested in 'abstract' understanding and explanation of the processes that produce these outcomes. As we have shown in the case studies, the expectations of the policy-making field influence the research issues in particular, but also the methods used. This way, the funding body ultimately influences the outcomes of research, although this is not a direct causal relationship, nor is it necessarily an effect intended by the funding body.

The interaction of the two discourses can be visualized (see Figure 1) as exchanges between different cyclical processes, each operating along the lines introduced for the research process by Latour and Woolgar $(1979,201)$. On the right-hand side of the figure, the original Latour and Woolgar research loop is depicted: researchers put equipment, data, arguments (knowledge) into the research process, and the application of these primary inputs results in research products (articles, books or reports). Articles may be read by peers and by decision-makers, leading to the credibility of the researcher as a good researcher, and to money and other resources (grants, tenure, etc.). With the aid of these resources, the researcher can start another round of the process of data collection, etc.

Analogous to the research cycle, a policy cycle can be proposed (on the left-hand side of the figure). Decision-makers, especially politicians, can be seen to put arguments and debates into a process of policy choices that often result in spending money. Through these policies they hope to obtain public recognition, credibility as good decision-makers, to get (re-)elected and to get the tax money they need to spend in another round of the policy game. The two different cycles or discourses, one could indeed say the different realities, meet although they have different views and interests. The links between these discourses or realities are, on the one hand, 


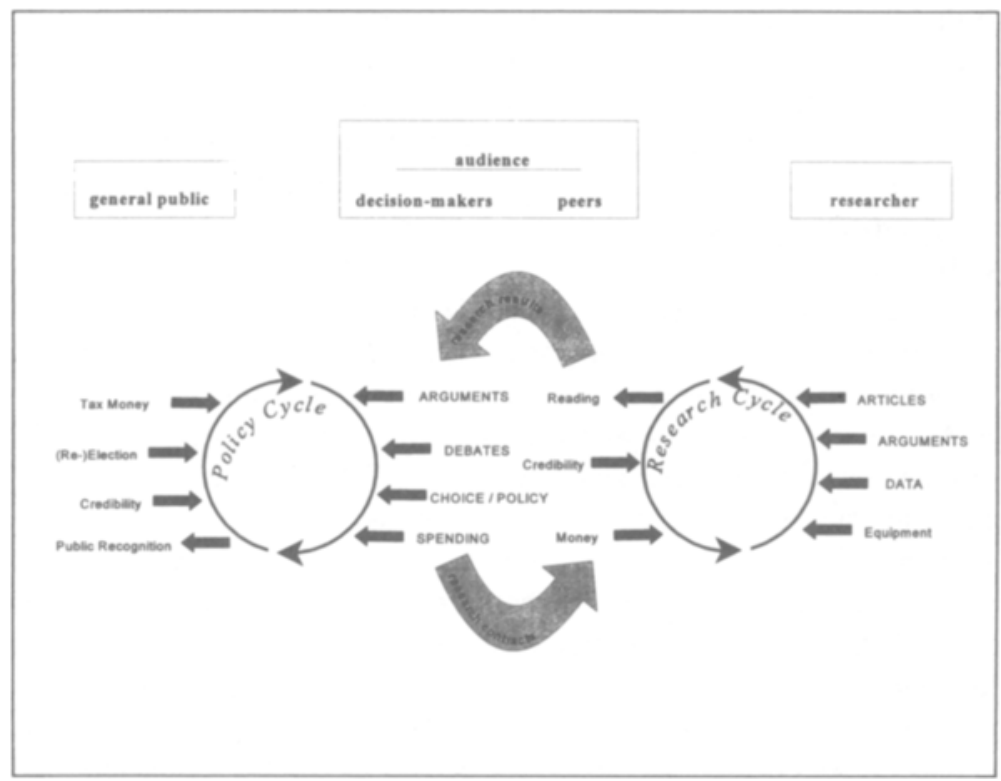

Figure 1. Policy discourse (policy cycle) and research discourse (research cycle) in the field of higher education

research results, where reading of articles or reports is turned into arguments for decision-makers, and on the other hand research contracts, where decision-makers spend money to obtain new research results they may use again. These are the two points where researchers and decision-makers have a common interest, although they both come to these points from a different angle, with different speeds (or time horizons), and are moving in different directions; they 'use a common situation for different purposes' (Wagner 1990, 300).

For the decision-maker, it is an exchange of money for arguments that are relevant to policy be it legitimation or support of the decision-maker's present or contemplated policy, or condemnation of the opponent's policy. We realize, of course, that this is an overly 'rationalistic' view of policy-making: commissioning research may have other functions in the policy cycle as well. In particular, it can be used to postpone making decisions. In general, we have touched here on the wide area of research utilization (Weiss 1972; Patton 1978; and many others). Our primary focus in this paper lies, however, on the effects of the relationship between the two discourses on the other party in this exchange, namely, the researcher. For the researcher, the link between the two discourses is an exchange of research results (concepts, data, correlations, explanations, theories) for money that can be used to support more research. We would like to argue that in the exchange of research results, it is not primarily the data, the figures and numbers, that are important. What happened during both the cases described, was that researchers created or introduced concepts that were applicable both in research discourse and in policy discourse. The 'quality culture' and 'working culture' serve as examples. 
These concepts, in turn, may have been instrumental in bringing about the more substantial further outcomes. More generally it seems that in the field of higher education the main task of the researchers is not to serve the decision-makers with instrumentally oriented data, but with concepts and perspectives on the functioning of higher education that can be used by policy-makers in higher education policymaking and in other societal discourses.

The link with the policy cycle puts pressure on the researcher, who, even as an individual, may feel the tension between the internal (research discourse based) motivations and interests, and the external (policy cycle based) expectations. Probably, the same applies to contract researchers in other fields of social sciences and humanities, too. In this way, the interplay between the discourses does not only create a drive towards publishing in general ('publish or perish'), but also a drive towards the creation of new concepts and perspectives.

\section{Acknowledgements}

For their helpful comments on an earlier version of this paper, the authors wish to thank Risto Eräsaari, Jim Fairweather and Frans van Vught.

\section{References}

Becher T. (1989). Academic Tribes and Territories. Intellectual enquiry and the cultures of disciplines. The Society for Research into Higher Education and Open University Press.

Becher, T. and Kogan, M. (1992). Process and Structure in Higher Education. London: Routledge.

Bernstein, R.J. (1988). Beyond Objectivism and Relativism: Science, Hermeneutics, and Praxis. Philadelphia: University of Pennsylvania Press.

Child, J. (1984). Organizations. London: Harper and Row.

Clark, B.R., (1983). The Higher Education System: Academic Organization in Cross-National Perspective. Berkeley: University of California Press.

Clark, B.R. and Neave, G. (eds.) (1992). The Encyclopedia of Higher Education. Oxford: Pergamon Press.

Cook, T.D. and Campbell, D.T. (1979). Quasi-experimentation: Design and analysis issues for field settings. Chicago: Rand McNally.

Fairclough, N. (1992). Discourse and Social Change. Cambridge: Polity Press.

Foucault, M. (1972). An Archaeology of Knowledge. London: Tavistock Publications.

Frederiks, M.M.H., Westerheijden, D.F. and Weusthof, P.J.M. (1994). 'Effects of Quality Assessment in Dutch Higher Education', European Journal of Education 29(2), 181-199.

Fulton, O. (1992). 'Higher Education Studies' in Clark, B.R and Neave, G. (eds.), The Encyclopedia of Higher Education. Vol 3. Oxford: Pergamon Press, 1810-1821.

Geertz, C. (1983). Local knowledge. Further Essays in Interpretive Anthropology. New York: Basic Books.

HBO Council (1990). Sectorale kwaliteitszorg HBO. The Hague: HBO Council.

Inspectorate of Higher Education [the Netherlands] (1992). De bestuurlijke hantering van de resultaten van de externe kwaliteitszorg 1989 in het wetenschappelijk onderwijs [The utilization of the results of the external quality assessment 1989 in university education]. De Meern: Inspectie Hoger Onderwijs. 
Heiskala, R. (1990). 'Sosiologinen kulttuuritutkimus' [Sociological Study of Cultures] in Mäkelä. K. (ed.), Kvalitatiivisen aineiston analyysi ja tulkinta [The Analysis and Interpretation of the Qualitative Data]. Helsinki: Gaudeamus, 9-29.

Kogan, M. (1989), Evaluating Higher Education. London: Jessica Kingsley Publishers in Association with the OECD.

Knorr-Cetina, K. (1981). The Manufacture of Knowledge. Oxford: Pergamon Press.

Konttinen, R. and Välimaa J. (1990). Free Allocation of Teaching Resources as an Element of Selfregulation Strategy. Paper presented at 12th European AIR Forum, 9-12 September, Lyon.

Kuhn, T.S. (1962 [1970]). The Structure of Scientific Revolutions. Chicago: University of Chicago Press.

Latour, B. and Woolgar, S. (1979). Laboratory Life. Beverly Hills: Sage.

Lieshout, R.H. and De Vree, J.K. (1985). 'How Organizations Decide', Acta Politica XX, 129-155.

Macdonell, D. (1986). Theories of Discourse: an introduction. Oxford: Basil Blackwell.

Ministry of Education and Science [the Netherlands] (1985). Hoger Onderwijs: Autonomie en kwaliteit [Higher Education: Autonomy and Quality].

Ministry of Education and Science [the Netherlands] (1993). Ontwerp Hoger Onderwijs en Onderzoek Plan 1994 [Draft Higher Education and Research Plan 1994].

Patton, M.Q. (1978). Utilization-Focused Evaluation. Beverly-Hills: Sage.

Pfeffer, J. (1981). Power in Organizations. Boston: Pitman.

Popper, K. (1959 [1980]). The Logic of Scientific Discovery (rev. ed.). London: Hutchinson.

Sallinen, A., Konttinen, R. and Panhelainen, M. (1993). Interactive Model of Self-Evaluation. Quality Assessment at the University of Jyväskylä-Pilot Study. Paper presented at the IMHE Seminar on Quality Management and Quality Assurance in Higher Education, Paris, 6-8 December 1993.

Välimaa, J. (1991), Flexibility and Free Allocation of Teaching Resources in the Cultures of Disciplines. Proceedings of 13th International EAIR Forum 1st-4th September 1991, Napier Polytechnic, Edinburgh, Scotland.

Välimaa, J. (1992). 'Faculty Cultures and Innovations - a case study', in Pentti Hakkarainen Pentti Määttä (eds.), Current Visions and Analysis on Finnish Higher Education System. Jyväskylä: University of Jyväskylä. Institute for Educational Research. Publication series B. Theory into Practice 75 .

Välimaa, J. (ed.) (1993). Toimintaa vai terapiaa? Työvelvollisuuskokeilu korkeakouluissa [Action or Therapy? Free allocation of teaching resources - experimentation in Finnish higher education]. Jyväskylä: University of Jyväskylä. Institute for Educational Research. Publication series B. Theory into Practice 81.

Välimaa, J. (ed.) (1994a). Kymmenen tarinaa opetuksesta. [Ten Stories on University Teaching]. Jyväskylä: University of Jyväskylä. Institute for Educational Research. Publication series B. Theory into Practice 86.

Välimaa, J. (1994b). 'A Trying Game: Experiments and Reforms in Finnish Higher Education'. European Journal of Education 29(2), 149-163.

Välimaa, J. and Vuorinen, P. (eds.) (1991). Työvelvollisuuskokeilun rypäleitä ja kimaroita. [Innovations in Teaching during the Experiment of Free Allocation of Teaching Resources as an Element of SelfRegulation Strategy]. Jyväskylä: University of Jyväskylä. Institute for Educational Research. Publication series B. Theory into Practice 65.

Van Dijk, T.A. (1985). Handbook of Discourse Analysis, 4 vols. London: Academic Press.

Van Vught, F.A. (1989). 'Creating innovations in higher education', European Journal of Education 24: 249-270.

Van Vught, F.A. and Westerheijden, D.F. (1993). Quality Management and Quality Assurance in European Higher Education: Methods and Mechanisms. Luxembourg: Office for Official Publications of the European Communities.

Vroeijenstein, T.I. and Acherman, H.A. (1990). 'Control Oriented versus Improvement Oriented Quality Assessment', in Goedegebuure, L.C.J., Maassen, P.A.M. and Westerheijden, D.F. (eds.) Peer Review and Performance Indicators: Quality Assessment in British and Dutch Higher Education. Utrecht: Lemma.

VSNU (1988). De evaluatie van het project proefvisitaties [Evaluation of the trial visitations project]. Utrecht: VSNU. 
VSNU (1990). Guide for External Program Review. Utrecht: VSNU.

Wagner, P. (1990). 'Social Sciences and Political Projects: Reform Coalitions Between Social Scientists and Policy-Makers in France, Italy and West Germany', in Wagner, P., Wittrock, B. and Whitley, R. (eds.), Discourses on Society, Vol. XV, Dordrecht: Kluwer Academic Publishers.

Wagner, P. and Wittrock, B. (1990). 'States, Institutions and Discourses: A Comparative Perspective on the Structuration of the Social Sciences', in: P. Wagner, B. Wittrock and R. Whitley (eds.), Discourses on Society, Vol. XV, Dordrecht: Kluwer Academic Publishers.

Weiss, C.H. (1972), 'Utilization of Evaluation', in Weiss, C.H. (ed.), Evaluating Action Programs. Boston: Allyn and Bacon.

Weusthof, P.J.M. (1989). 'Zelfevaluatie: wat, hoe en waartoe?' ['Self-Evaluation: What, how and why?'], Tijdschrift voor Hoger Onderwijs 7, 148-159.

Whitley, R. (1984), The Intellectual and Social Organizations of the Sciences. Oxford: Clarendon Press. Yin, R.K. (1989). Case study research: Design and methods. Rev. ed. Newbury Park: Sage Publications. 